\title{
ФЕНОМЕН ГЛОБАЛЬНЫХ ПРОБЛЕМ В СОВЕТСКОЙ НАУКЕ (К истокам глобалистики)
}

\author{
Лось В. А.
}

В статье проводится анализ становления и динамики исследований глобальных проблем в советской науке в период «золотой декады» (1980-1990), в рамках которой закладывались основания постсоветской глобалистики. Вскрываются теоретические основания и методология изучения глобальных проблем, их адаптация к тогдашним политическим реалиям. Выделяются основные направления изучения феномена глобальных проблем. Рассматривается организаџионная структура их исследования.

Ключевые слова: глобальные проблемы, интернационализация, глобализация деятельности, глобальное мышление, новое политическое мышление, организационные структуры, глобалистика.

The article analyzes the formation and dynamics of research on global problems in Soviet science during the 'golden decade' (1980-1990), within the framework of which the foundations of post-Soviet globalistics were laid. The theoretical foundations and methodology of studying global problems as well as their adaptation to the political realities of that time are revealed. The main directions of studying the phenomenon of global problems are highlighted. The organizational structure of their research is considered.

Keywords: global problems, internationalization, globalization of activity, global thinking, new political thinking, organizational structures, globalistics.

Эпоха феномена глобальных проблем началась в советской науке с публикации классических монографий В. В. Загладина и И. Т. Фролова [1981] и коллективной монографии под редакцией Н. Н. Иноземцева [Глобальные... 1981], а условно закончилась с выходом в свет фундаментального труда под редакцией И. Т. Фролова [Социализм... 1987]. Очевидно, что в советской реальности любая инновационная система знаний должна была быть увязана с доминирующей идеологией.

\section{Марксистские основания исследования глобальных проблем}

Марксизм заложил основания исследований процессов общечеловеческого характера, связав их с интернационализацией. Она трактуется как форма развития капитала, обусловливающая активный процесс преодоления национальной замкнутости как материального, так и духовного производства.

Основоположники марксизма связывали «великое цивилизаторское влияние» капитала с тем, что плоды деятельности отдельных наций становятся «общим до-

* Лось Виктор Александрович - д. ф. н., профессор, действительный член Российской экологической академии. E-mail: Victor943@icloud.com.

Век глобализации 3/2021 45-59

DOI: $10.30884 / v g l o b / 2021.03 .04$ 
стоянием»; разрушаются национальные предрассудки и ограничения; снимаются традиционное, «самодовольно замкнутое» в определенных границах удовлетворение существующих потребностей и воспроизводство «старого образа жизни». Более того, разделение труда между отдельными нациями, странами и государствами, делающее невозможным их обособленное производственно-хозяйственное и социокультурное функционирование, преодолевает «первоначальную замкнутость» отдельных социумов - история превращается в «мировую историю».

Конструктивное стремление капитала к интернационализации экономических, социальных и культурных процессов наталкивается, однако, согласно марксистской доктрине, на имманентные препятствия, обусловленные его сущностью. А именно: экспансия капитала ведет к дальнейшему «отчуждению человека», то есть результаты его труда превращаются в универсальное средство «закабаления» индивидуума.

Выявляется парадоксальная ситуация. С одной стороны, усиливается процесс интернационализации всех, в сущности, сторон и сфер человеческой деятельности и существования - осуществляется всесторонняя связь и всесторонняя зависимость наций друг от друга. С другой стороны, динамизм социума в условиях рыночных отношений оборачивается против личности, ибо человеческая жизнь низводится до уровня «простой» материальной силы.

Развитие и расширение процессов интернационализации с неизбежностью ведет, в соответствии с марксистской доктриной, к логическому (и историческому) «снятию» капиталистических отношений. Если основоположники марксизма уже в формах европейской интернационализации усматривали «призрак коммунизма», то на рубеже XIX-XX вв., в условиях «зрелого капитализма», В. И. Ленин подмечал признаки будущего «социалистического единства мира»; формирование «общих экономических всемирных отношений»; реализацию тенденции создания единого «всемирного хозяйства как целого».

При этом марксизм обращал внимание и на социально-природный контекст развития. Выявляется диалектический характер взаимосвязи «истории природы» и «истории людей». Иными словами, речь шла о том, что «природные основания» изменяются в процессе исторической динамики, а характер и направления исторического процесса обусловливаются природными условиями. Во все эпохи феномен воспроизводства рассматривается как результат взаимодействия деятельности социума и «производительной силы природы». Именно в процессе труда осуществляется «обмен веществ» в системе «человек - социум - биосфера». Специфичность этого «обмена» определяется не столько непосредственно биологической активностью индивидуума, сколько способом материального (и духовного) производства, то есть обусловливается установками социума - его структурой, типом организации, социокультурными стереотипами и т. п. Всякое производство есть, с одной стороны, присвоение индивидуумом «предметов природы» согласно определенной «общественной форме»; а с другой стороны, в процессе производства индивидуум действует так, как «сама природа».

И тем не менее марксистский анализ динамики системы «человек - социум природа» исходит из того, что в процессе естественно-исторического развития 
усиливаются противоречия между элементами системы. Обострение противоречий между человеком (социумом) и природой трактуется, однако, не как результат труда вообще, но - «отчужденного труда», в основе которого лежит экономическое отчуждение. Продукт труда противостоит производителю как чуждая сила, ибо принадлежит не ему, а собственнику. При этом культурно-поведенческие стереотипы рыночных отношений (масштабы деятельности, рост социальных потребностей и др.) ведут в условиях капитализма, в соответствии с марксистской доктриной, к опасному обострению социально-природных противоречий.

Напротив, теория «научного социализма» исходит из того, что «ассоциированные производители» выйдут на уровень взаимоотношений с природой в «адекватной ей форме». Иначе говоря, преодоление антагонистических противоречий в системе «человек - социум - природа» связывается, в теории марксизма, с переходом от капитализма к социализму (коммунизму), где, в соответствии с теорией, должен быть реализован принцип рационального взаимоотношения всех элементов социоприродной системы.

Особенно это касается интерпретации феномена человека. Более того, марксизм, стремясь приблизиться к пониманию сущности человека, предложил жестко «социализированный» подход к «освобождению личности».

Определение сущности человека связывается с осуществлением его трудовой функции, при реализации которой и развиваются специфические человеческие качества. При этом труд рассматривается не только как условие «обмена» между человеком и природой, как средство жизни, но и как форма самоутверждения личности. Иначе говоря, труд выступает как общественное отношение к природе, а общественный характер человека необходимо включается в понимание его сущности. Более того, выявление и обоснование биосоциальной сущности человека прежде всего выражается, согласно марксизму, в прогрессе способов деятельности. Способ производства рассматривается не только с точки зрения воспроизводства «физического существования индивидов»; в еще большей мере это определенный вид их жизнедеятельности. В таком контексте эволюция производства трактуется как «раскрытая книга человеческих сущностных сил» [Маркс, Энгельс 1955].

Человек предстает как «постоянная предпосылка истории», ее «продукт и результат». Многообразие человеческой природы - процесс развития личности в результате материальной и духовной деятельности: общения, обучения, образования, воспитания и т. п. Следовательно, человек - итог процесса освоения и воспроизведения предшествующего социокультурного опыта человечества. И если цель капитализма (по К. Марксу) - «производство ради производства», то целевая установка социализма (и коммунизма) - развитие человека. Классики марксизма утверждали в «Манифесте Коммунистической партии» (1848 г.): в обществе будущего каждый индивидуум получит возможность развивать свою «человеческую природу», а «свободное развитие каждого» станет условием «свободного развития всех».

Однако объективные исследования уже в XX в., особенно в его второй половине, реально показывали, что социально-философская доктрина марксизма, отражая реалии XIX в., утрачивает свою адекватность современным мировым трен- 
дам. Это в полной мере касается интерпретации всего «блока вопросов» (о них речь шла выше), составляющих «ядро» марксистской интерпретации системы глобальных проблем, а именно: интернационализация производственно-хозяйственной и социокультурный деятельности, острота взаимоотношений общества и среды его обитания, феномен человека как интегрирующий фактор динамики развития цивилизации.

\section{Контуры «нового политического мышления»}

Марксизм отчетливо вскрыл причины «отчуждения» природы в условиях динамично развивающихся рыночных отношений, утверждая при этом, что «феномен отчуждения» не позволит в рамках капитализма выйти на уровень рационализации системы «человек - социум - природа». В действительности же рационализация элементов социально-экологической системы как необходимое условие преодоления биосферной напряженности стала осуществляться в рыночных условиях. Именно «развитой капитализм» создал экономическую основу для реальной «экологизации» рыночных отношений, действительного повышения «качества жизни» и выхода на уровень конструктивного человеческого развития.

Практика «реального социализма» привела, к сожалению, к догматизации марксистской доктрины, «разрыву» между ее теоретическими положениями, сформулированными для середины XIX в., и реалиями, характерными для XX в. Очевидно, однако, что марксизм, занимая свое место в пантеоне истории и не претендуя на абсолютизацию интерпретации тенденций современного мирового развития, тем не менее сыграл существенную роль в генезисе советских исследований глобальных проблем.

Опираясь на марксистские традиции и развивая их в новых международнополитических условиях, XXVII съезд КПСС (1986 г.) провозгласил глобальные проблемы как значимую социально-политическую реальность. Позднее этот тезис был положен в основание представлений о «новом политическом мышлении» [Горбачев 1987]. В его рамках преодолевались традиционные идеологические стереотипы, базирующиеся на конфронтационной идеологии о «двух системах» (и «двух мирах»). С этих позиций вся ответственность за обострение противоречий глобального масштаба, в том числе за гонку вооружений, бедственное экономическое положение стран третьего мира, мировой продовольственный дефицит и др., возлагалась на западные страны. С другой стороны, утверждалось, что использование «преимуществ социализма» с его плановой организацией деятельности и гуманистическим мировоззрением является реальной предпосылкой преодоления противоречий национально-регионального и глобального масштабов. Более того, позитивные перспективы мировой цивилизации связывались с продвижением человечества к коммунистическому будущему, где в полной мере должен раскрыться потенциал человеческой личности.

В условиях эрозии идеологического догматизма формирующееся «новое политическое мышление», пытаясь дать ответы на глобальные вызовы цивилизации, балансирует на грани марксистских стереотипов и идеологических инноваций. Отметим некоторые из его элементов.

Во-первых, признание общечеловеческих ценностей (при этом классовый подход отнюдь не отвергается) при анализе динамики исторического развития. 
Во-вторых, трактовка международных отношений на основе баланса интересов, учитывая зависимость и во многом «целостность мира». В-третьих, опора на политику мирного сосуществования государств с различным общественным строем как приоритетная стратегия, обеспечивающая перспективное выживание цивилизации и ее конструктивную историческую динамику.

В рамках концепции «нового политического мышления» разрабатывалась стратегия выхода на уровень социализма с «человеческим лицом» для решения проблем общечеловеческого характера, новых форм взаимоотношений государств с различным политическим устройством. Несмотря на сохранение противоречий современного мирового развития и существенные различия (политические, экономические, социокультурные и др.) между государствами, во все большей мере внимание акцентируется не на дифференциальных, а на интегративных тенденциях. Проблема выживания человечества рассматривается как приоритетная, а политика мирного сосуществования государств с различным общественным строем - как единственно возможный путь, обеспечивающий международную безопасность.

Для идеологической респектабельности феномена глобальных проблем используется не только теоретическая база марксизма. Для подкрепления статуса политического мышления нового типа из ранних ленинских работ было извлечено забытое прежде положение об известном «доминировании» интересов «общественного развития» над «интересами пролетариата». «Общечеловеческий подход», присутствующий в работах раннего Маркса, отнюдь не составляет основания зрелого марксистского понимания динамики всемирно-исторического развития, где действуют доминирующие «классовые силы». «Общечеловеческий» потенциал марксизма, нивелированный в прошлом, оказался востребованным в условиях, когда под воздействием усиливающихся кризисных социально-экономических процессов возникла необходимость трансформации «реального социализма».

Идея «нового политического мышления» прежде всего стала реализовываться в военно-политической сфере. Публиковались данные, из которых следовало, что использование лишь незначительной части уже накопленного мирового ядерного потенциала ставит цивилизацию на грань катастрофы. Более того, ядерная конфронтация между двумя «сверхдержавами» (СССР и США) оборачивалась непосильным для мировой экономики, особенно для экономического потенциала «развитого социализма», бременем расходов. Ориентиры политического мышления нового типа формулировались следующим образом: если человечество не сумеет найти механизмы управления гонкой вооружений, то есть предотвратить неизбежность ядерной войны, то не только будет разрушена материальная (и культурная) основа современной цивилизации, но и станет реальностью тотальная экологическая катастрофа, ведущая к деградации и гибели всего живого, в том числе и человека.

Впервые, видимо, в современной истории выводы науки принимались во внимание в процессе принятия политических стратегических решений. Так, для их обоснования был использован утраченный прежде Манифест Рассела - Эйн- 
штейна (1955), под которым свои подписи поставили крупнейшие мировые ученые (Ф. Жолио-Кюри, Л. Полинг и др.) В нем зафиксированы мысли, не потерявшие, к сожалению, и поныне своей актуальности.

Во-первых, подчеркивается возможность «всеобщей гибели» человечества в результате применения термоядерного оружия. Во-вторых, обращается внимание на то, что разногласия в тогдашнем мире (между Западом и Востоком, коммунизмом и антикоммунизмом, «белыми» и «черными» и др.) необходимо пытаться разрешить не «силой оружия», а «мирными средствами». Спустя тридцать лет эти же положения доказывались с опорой на выводы модели «ядерной зимы», в рамках которой обмен термоядерными ударами между сверхдержавами приводит к глобальной экологической (и социальной) катастрофе.

И если в середине 50-х гг. гонка холодной войны еще только набирала обороты, то к концу 80-х гг. ее негативные последствия для цивилизации в целом и ее составных частей выявлялись все более отчетливо.

В условиях перестройки идея мирного сосуществования государств с различным устройством становится фактором реальной политики. Это привело к поддержке мировым сообществом радикальных изменений, происходящих в условиях «реального социализма».

\section{Основные направления исследований глобальных проблем}

$\mathrm{C}$ середины 70-х гг. XX в. в ведущих партийных и общественно-политических изданиях (газета «Правда», журналы «Коммунист», «Проблемы мира и социализма» и др.), публикации в которых носили, как правило, директивный характер, была представлена целая серия материалов, дающих марксистскую интерпретацию глобальной проблематики, в частности, выявляющих взаимосвязь общечеловеческих и классовых подходов в оценке исторического развития. Ведущий философский журнал «Вопросы философии» опубликовал материалы ряда круглых столов, посвященных обсуждению как отдельных глобальных проблем (например, экологических), так и их системы в целом. В начале 80-х гг. вышли в свет первые монографические исследования, авторы которых (В. В. Загладин и И. Т. Фролов) входили в рабочие группы по подготовке соответствующих разделов XXVII съезда КПСС, определявших в значительной мере до начала 90-х гг. основные направления исследований в области глобальных проблем в нашей стране.

В этот период активно действовали научные коллективы и отдельные специалисты, разрабатывающие различные аспекты глобальных проблем, исследования которых приобретали вместе с тем отчетливую комплексную направленность. Условно выделим несколько доминирующих направлений исследований.

Философско-методологическое направление. Разработка общетеоретических аспектов глобальной проблематики.

Фундаментальный характер приобрела классическая классификация глобальных проблем, предложенная на рубеже 70-80-х гг., сохранившая и поныне свой статус. При этом прошедшие десятилетия представили свои дополнения. К примеру, неизмеримо повысился масштаб социальных сетей, которые оказывают ра- 
дикальное воздействие на индивидуальное (и общественное) сознание. Разрабатывались методы (системный подход, глобальное моделирование и др.), которые можно было бы применять для адекватного анализа имманентно комплексной (интегральной) проблематики. В этом контексте рассматривалась тенденция к интеграции современного научного знания как одного из определяющих факторов, обеспечивающих адекватный анализ проблем подобного уровня системной сложности.

Военно-стратегическое направление. Анализ глобальных последствий гонки вооружений и реальной угрозы мировой термоядерной катастрофы.

Потенциальная возможность обмена термоядерными ударами между сверхдержавами и реальность соответствующих негативных последствий, ставящих под угрозу само существование и даже выживание цивилизации, до недавнего времени трактовалась как «глобальная проблема номер один». Более того, результаты глобального моделирования потенциальной термоядерной катастрофы (модель «ядерная зима») стали одним из важных факторов, усиливающих реализацию стратегии мирного сосуществования государств различных (и даже противоположных) систем.

Социально-экологическое направление. Наиболее разрабатываемая (после военно-стратегического направления) сфера глобальных исследований.

С конца 60-х - начала 70-х гг. мировая социально-экологическая ситуация стала рассматриваться как острейшая глобальная проблема современности. При этом масштабы и характер человеческой деятельности оценивались в качестве определяющего фактора опасной для человека (и биосферы) деградации окружающей среды. С одной стороны, анализируются причины обострения мировой биосферной напряженности, ассоциируемые с типом техногенной цивилизации, демографическими процессами, ростом общественных потребностей и др. С другой стороны, предлагаются механизмы снятия остроты социально-экологических противоречий (повышение «степени замкнутости» деятельности, «экологизация» мышления индивида и т. п.).

Научно-техническое направление. Динамика научно-технического развития рассматривается в контексте глобальной проблематики.

Выявляется диалектика взаимосвязи элементов системы «наука - техника производство». Исторически сложившаяся ориентация научно-технического прогресса (масштабность деятельности социума, преувеличение статуса технократизма и др.) трактуется как существенный фактор (помимо положительных моментов прогресса), усугубляющий остроту противоречий современной цивилизации. С другой стороны, именно конструктивная направленность современных исследований и разработок, выход их на новый уровень (биотехнология, информатизация и т. п.) рассматриваются как возможность научно-практического разрешения и отдельных глобальных проблем, и их системы в целом.

Социально-экономическое направление. Оценивается специфика проявления глобальных противоречий в различных региональных условиях, их особенности в развитых и развивающихся странах. При этом акцент ставился в советских (идеологических) условиях на по крайней мере трех тезисах. 
Во-первых, утверждалось, что острота и масштабность обострения современной системы глобальных проблем с несравненно большей, чем в предшествующие исторические периоды, силой вскрывают социально-экономическую ограниченность капиталистических принципов развития. Во-вторых, доказывалось (и это в известной степени соответствовало действительности), что именно капиталистические формы хозяйствования, и в особенности колониализм (и неоколониализм), несут всю полноту ответственности за остроту региональных противоречий глобального масштаба (нищета, голод, неграмотность населения и др.). И, в-третьих, постулировалось (позднее это положение существенно корректировалось), что только в условиях «реального социализма» создаются объективные предпосылки (экономические, социальные, политические и т. п.) для позитивного разрешения всей системы глобальных проблем, преодоления существенных «ножниц» в уровнях развития между странами «третьего мира» и промышленными государствами.

Прогностическое направление. Экстраполяция и оценка футурологических трендов современных мировых процессов. Выделим две группы соответствующих исследований.

В рамках одной из них на основе рассмотрения западных представлений о контурах будущего, в том числе и тех, которые излагались в докладах Римскому клубу, давался критический анализ возможностей капитализма адекватно преодолеть глобальные исторические противоречия. Западная футурология критиковалась за абстрактность и утопичность, социальную ограниченность, «технократический оптимизм», «экологический пессимизм» и др. Впрочем, постепенно западные модели глобального будущего получали более адекватную (объективную, отнюдь не идеологическую) интерпретацию.

Вторая группа исследований связана с разработкой позитивных перспектив социализма, экстраполяцией современных глобальных трендов в контексте возможного социалистического будущего человечества. И если в начале 80-х гг. прогностические перспективы цивилизации связывались с реализацией социалистического сценария, то к началу 90-х гг. соответствующие глобальные построения не носили (как прежде) безусловного характера.

Подчеркнем специфические особенности советских разработок в области глобальных проблем. Во-первых, стремление оценить мировые процессы в контексте их соответствия (или противоречия) марксистским стереотипам; во-вторых, преимущественно критический анализ результатов исследований, полученных западными специалистами; в-третьих, абсолютизация достижений «реального социализма», его исторических перспектив, что ограничивало возможности объективных разработок, в том числе и в области глобальных проблем.

И тем не менее за десятилетие (80-90-е гг.) советские исследователи сделали немало:

- сформировалось новое направление (позднее названное глобалистикой) отечественной науки в процессе взаимодействия (интеграции) социально-гуманитарного, естественно-научного и технико-технологического знания; 
- разработаны научные методы (системный подход, глобальное моделирование и др.), эффективно применяемые для анализа сложных систем различной степени и масштаба интеграционного статуса;

- представлены сценарии динамики не только отдельных глобальных проблем, но и их системы в целом как в российском, так и в мировом измерении;

- результаты глобальных исследований (в частности, модель «ядерная зима»), воспринятые лицами, принимающими решения, оказали существенное влияние на мировой и национальный политический климат (политика мирного сосуществования, новое политическое мышление).

\section{Глобальные исследования: организационно-управленческие механизмы}

В течение 80-х гг. ХХ в. инициативы исследований в сфере глобальных проблем и их координация в значительной степени были связаны с деятельностью Научного совета при Президиуме АН СССР по философским и социальным проблемам науки и техники (И. Т. Фролов) и его секции «Глобальные проблемы» (В. В. Загладин). Отметим основные направления их деятельности.

Организация и проведение обсуждений на базе ведуцих научных учреждений Академии наук. Структура обсуждений подобного рода выглядела примерно следующим образом. Сначала руководитель учреждения, где проводилось заседание, его ведущие научные сотрудники выступают с докладами и сообщениями, в которых рассматривались результаты исследований, связанных с изучением различных аспектов глобальных проблем (в контексте интересов данного научного учреждения); формулировались стратегические направления и ориентиры возможных перспективных глобальных исследований. В рамках проводившейся далее дискуссии отмечались спорные вопросы, намечались перспективы совместных разработок и т. п. Материалы дискуссии, как правило, готовились к публикациям как в специализированных, так и в общетеоретических изданиях.

Институт мировой экономики и международных отношений. Являлся одним из лидеров исследования глобальных проблем в нашей стране.

Руководитель проекта глобальных разработок ИМЭиМО М. М. Максимова акцентировала внимание на теоретико-методологических сторонах изучения глобальных проблем, их взаимосвязи как с отдельными проблемами глобального масштаба, так и с их системой [Максимова 1986]. Специалисты института представили ее комплексный анализ, а именно: рассмотрение международных и национальных механизмов предотвращения термоядерной войны; конкретно оценивали перспективы мировой демографической ситуации, специфику продовольственной сырьевой базы в различных регионах мира, существенное внимание уделяли рассмотрению мировой социально-экологической ситуации и др. В заключении был предложен мировой сценарий развития цивилизации к началу XXI в.

Институт географии. Особенное внимание уделяется изучению взаимоотношений человека (социума) и среды его обитания.

Директор института академик И. П. Герасимов сделал доклад о фундаментальном значении географии («конструктивная география») в системе современ- 
ного научного знания, ее прогностическом лидирующем статусе [Герасимов 1976]. Ведущие сотрудники института (А. Г. Доскач и др.) подчеркивали значение обострения мировой экологической ситуации в общей системе глобальных проблем. Много внимания уделялось дискуссии о возможных мировых трендах, связанных с радикальными изменениями климата в планетарных масштабах. Был сделан прогноз динамики мировой и региональных социально-экологических ситуаций.

Институт научной информаџии по общественным наукам. Сбор и анализ обширных публикаций по глобальной проблематике.

В докладе директора института академика В. А. Виноградова обращалось внимание на то, что в современном мире информатизация приобретает планетарный характер, являясь базисным элементом динамики науки и социальной практики. Информатизация и глобализация выступают единым компонентом развития социума, способствуя повышению статуса интегративных тенденций в динамике цивилизации [Виноградов 1986]. Участники круглого стола знакомились и обсуждали те материалы по глобальной проблематике, которые готовились сотрудниками института.

Круглый стол в МГУ им. М. В. Ломоносова. Знакомство студентов с феноменом глобальных проблем.

В основе дискуссии была лекция профессора Д. Медоуза [1991], который рассказал не только об особенностях проекта «Пределы роста» (элементы которого уже были известны многим студентам), но и о перспективных направлениях глобальных исследований. В своем выступлении Медоуз подтвердил выводы модельных построений, в соответствии с которыми человечество, если не изменить тренды развития, реально приближается к состоянию коллапса.

Всесоюзный научно-исследовательский институт системных исследований. Разработка под руководством директора института Д. М. Гвишиани системы моделирования глобальных процессов [Гвишиани 1977].

Обсуждение открыл один из руководителей проекта В. А. Геловани, который ознакомил участников круглого стола с разработанной человеко-машинной системой моделирования глобальных процессов как взаимосвязью формализованных и неформализованных элементов. С использованием мирового опыта (работы Дж. Форрестера и др.) была построена модель глобальной системы на основе взаимодействия методов имитационного моделирования и сценарных построений [Геловани, Юрченко 1990].

Глобальная (мировая) система трактовалась докладчиком как совокупность региональных и национальных подсистем, которые определялись на основе следующих параметров: народонаселение (масштабы, темпы роста, структура и др.); продовольствие (динамика производства, распределения, потребления); экономика (особенности производства, потребления, распределения и накопления); природные ресурсы (региональное распределение и др.); среда обитания (характеристики атмосферы, климата, животного мира и др.); научно-технический прогресс (новые технологии); механизмы регулирования собственности (принципы собственности, типы социального регулирования). Моделируемая система носит 
столь сложный характер, заметил докладчик, что для ее эффективного описания и принятия адекватных управленческих решений недостаточно использовать только формальные методы. Речь идет о сочетании машинного подхода и сценарного описания.

Докладчик представил предварительные результаты исследовательского проекта, начатого в середине 80-х гг., под названием «На пороге третьего тысячелетия (Глобальные проблемы в процессе развития СССР)». На основе человекомашинного метода моделирования мирового и национально-регионального развития намечались контуры динамики мира и нашей страны до 2000 г.

Конечно, реальные изменения мировой социально-политической ситуации (например, распад стран социалистического содружества, развал СССР) не могли быть учтены на данном этапе проекта. И это, очевидно, снизило его влияние на национальное общественное мнение, политическое сознание общества. И тем не менее представленный метод человеко-машинного моделирования глобальных систем, опирающийся на фундаментальную теорию социально-экономического развития современного социума, является одним из важнейших способов познания динамики социального развития сложных объектов. Адекватное его применение - один из элементов выхода на уровень эффективных управленческих решений на национально-региональном и глобальном уровнях.

Вычислительный изентр Академии наук. Одно из базовых научных учреждений по разработкам компьютерного моделирования глобальных процессов в биоcфepe.

Острота мировой социально-экологической ситуации актуализировала разработку моделирования процессов в экосистеме глобального масштаба. Под руководством академика Н. Н. Моисеева была предложена система моделей, в рамках которой описывается естественная циркуляция вещества, а именно: геохимические циклы, климат и человеческая активность. Это и стало основой его выступления на круглом столе [Моисеев и др. 1985].

В рамках блока «Биота» была представлена модель системы геохимических циклов (азот, кислород и вода) с учетом биотического круговорота; наиболее подробно, уточнил докладчик, представлен круговорот углерода. В блоке «Климат» анализировались гидродинамические процессы взаимодействия атмосферы и Мирового океана, возможные изменения атмосферных температурных показателей. Блок «Человеческая активность», пояснял Н. Н. Моисеев, разработан пока в наименьшей степени; в его рамках предполагается учет возможного воздействия основных социально-экономических факторов (производство, аграрная система, трудовые ресурсы) на динамику биосферных процессов. Речь идет, заключил докладчик, пока лишь об учебной модели биосферы, в которой акцент сделан на более углубленном учете социально-экологических факторов.

Сотрудники центра подробно говорили о разработанной модели «Ядерная зима», уже представленной научному сообществу. Коллектив советских специалистов (Н. Н. Моисеев, В. В. Александров и др.) совместно с западными учеными (К. Саган и др.) дали оценку возможных глобальных климатических изменений в результате обмена термоядерными ударами между потенциальными противниками - сверхдержавами (СССР и США). 
Суть модели, как поясняли специалисты, состоит в следующем. Анализируются изменения атмосферного температурного режима в процессе сгорания в результате потенциального термоядерного удара - различных объектов биосферы, как природных (лесные массивы), так и социокультурных (хранилища топлива, индустриальные центры, жилища и др.). В соответствии с расчетами, в результате аэрозольного эффекта прогнозируется существенное и длительное похолодание атмосферы Земли (соответствующие конкретные цифры зависят от масштабов ядерного удара, характера сгорающих объектов и т. п.), что приведет к значительному ухудшению естественной среды обитания всего живого, в том числе и человека.

Проведение крупных научных форумов. Отметим два из них. А именно: Всесоюзный симпозиум «Марксизм-ленинизм и глобальные проблемы современности» (Москва, июнь 1983 г.) и Всесоюзная конференция «Социальные и методологические проблемы научно-технического прогресса (Москва, ноябрь 1984 г.).

Если на симпозиуме рассматривалась, в сущности, вся система глобальных проблем в их взаимосвязи (и взаимозависимости) с современными и прогностическими трендами, то на конференции особое внимание было сконцентрировано на выявлении роли науки и техники в разрешении противоречий глобального масштаба, возникающих перед современной цивилизацией, приближающейся к XXI в. В научных дискуссиях как на симпозиуме, так и на конференции приняли участие крупнейшие отечественные ученые, в том числе академики Н. Г. Басов, М. И. Будыко, В. А. Кириллин, М. А. Стырикович, В. А. Энгельгардт и др. Обсуждение различных аспектов глобальных проблем, выявление роли научно-технического прогресса в их разрешении сочетались с разработкой соответствующих рекомендаций.

Отметим и участие в международных форумах. Выделим конференции «Социализм и глобальные проблемы» (Прага, июнь 1985 г.) и «Экология и мир» (Варна, август 1986 г.). В них участвовали специалисты из различных стран, которые подчеркивали, в частности, необходимость укрепления международного сотрудничества в решении проблем глобального масштаба. Особенно активно обсуждались проблемы предотвращения мировой термоядерной катастрофы и преодоления кризисных явлений в глобальной системе «человек - социум - биосфера».

Научно-исследовательская деятельность. Выделим два ее направления: издание материалов соответствующих научных собраний и подготовка коллективных монографических исследований.

Практически каждое крупное научное мероприятие получало комплексную информационную поддержку. Покажем это на примере организации симпозиума «Марксизм-ленинизм и глобальные проблемы современности».

Во-первых, материалы, предварявшие проведение симпозиума, были изданы в типографии ИМЭиМО АН (в двух выпусках). Во-вторых, в журнале «Вопросы философии» (1983 г., № 12) был представлен подробный отчет об основных идеях симпозиума. И, в-третьих, было подготовлено фундаментальное научное издание материалов симпозиума (1985 г.). 
Назовем некоторые монографические исследования, подготовленные при поддержке Совета (и секции): том «Глобальные проблемы» - заключительная книга 20-томной серии «Земля и человечество. Страны и народы» (Мысль, 1985 г.), где ведущие отечественные специалисты анализируют все систему современных процессов глобального масштаба; книга «Горизонты экологического знания» (Наука, 1986 г.) - коллективная монография, посвященная оценке современного состояния и динамики системы «человек - социум - биосфера» в исторической перспективе; издание «Социализм и прогресс человечества. Глобальные проблемы цивилизации» (Политиздат, 1987) - монографическая работа крупнейших отечественных ученых, где подводится определенный итог исследований в области глобальных проблем.

Информационно-пропагандистская работа. Распространение научных знаний в сфере глобалистики.

Эта работа велась в сотрудничестве с Всесоюзным обществом «Знание». Отметим несколько ее направлений.

Во-первых, проведение в Центральном лектории общества в течение двух сезонов (1985-1987 гг.) цикла лекций, в рамках которых обсуждалась вся современная система глобальных проблем, перспективы их развития. В качестве лекторов выступали крупнейшие отечественные ученые и специалисты.

Во-вторых, этот опыт распространялся в масштабах страны. Соответствующие лекционные циклы проводились в столицах ряда союзных республик (в Алма-Ате, Ашхабаде и др.).

В-третьих, деятельность секции глобальных проблем освещалась в публикациях ведущих научных изданиях - «Вопросы философии», «Общественные науки», «Философский науки», в материалах Агентства печати «Новости» и др.

\section{Заключение}

Распад «советской империи» непосредственным образом сказался на статусе глобальной проблематики. К числу причин относительного снижения интереса к глобальным исследованиям следует отнести: теоретический вакуум, возникший после отказа от доминанты марксистской идеологии; доминирование российского подхода по отношению к мировым явлениям при глобальных построениях; организационно-финансовые трудности, обусловленные определенным снижением статуса науки, и др.

Однако на рубеже XX-XXI вв. возрождается несколько снизившийся к началу 90-х гг. интерес к глобальной проблематике [Глобалистика... 2003; 2006 и др.]. Поток соответствующих публикаций соответствует законам геометрической прогрессии.

К началу XXI в. глобальные проблемы, рассматриваемые в динамике исторического развития (глобализация), становятся объектом изучения активно формирующейся интегральной системы современного научного знания (глобалистика). Глобалистика в своих методологических принципах опирается и на позитивный опыт глобальных исследований советского периода. 


\section{Литература}

Виноградов В. А. Общественные науки и информатизация. М. : Наука, 1986.

Глобалистика: Международный междисциплинарный энциклопедический словарь. М., СПб. Нью-Йорк : Элима, Питер, 2006

Глобалистика: Энциклопедия / гл. ред. И. И. Мазур, А. Н. Чумаков. М. : Диалог, 2003.

Глобальные проблемы современности / под ред. Н. Н. Иноземцева. М. : Мысль, 1981.

Горбачев М. С. Перестройка и новое мышление. М. : Политиздат, 1987.

Загладин В. В., Фролов И. Т. Глобальные проблемы современности: научный и социальные аспекты. М. : Международные отношения, 1981.

Геловани В. А., Юрченко В. В. Проблемы компьютерного моделирования. М. : МНИИПУ, 1990.

Герасимов И. П. Советская конструктивная география. М. : Наука, 1976.

Гвишиани Д. М. Методологические проблемы моделирования глобального развития. М., 1977.

Максимова М. М. Европейское сообщество: регулирование интеграционных процессов. М. : Наука, 1986.

Маркс К., Энгельс Ф. Немецкая идеология / К. Маркс, Ф. Энгельс // Соч.: в 55 т. 2-е изд. Т. 3. М. : Гос. изд-во полит. лит-ры, 1955. С. 7-544.

Медоуз Д. Пределы роста. М. : Изд-во МГУ, 1991.

Моисеев Н. Н., Александров В. А., Тарко А. М. Человек и биосфера: Опыт системного анализа и эксперименты с моделями. М. : Наука, 1985.

Социализм и прогресс человечества. Глобальные проблемы цивилизации / под общ. ред. И. Т. Фролова. М. : Политиздат, 1987.

\section{References}

Vinogradov V. A. Obschestvennie nauki i informatizatsiya [Social Sciences and Informatization]. Moscow : Nauka, 1986.

Globalistika: Mezhdunarodnyj mezhdistsiplinarnyj entsiklopedicheskij slovar' [Globalistics: International Interdisciplinary Encyclopedic Dictionary]. Moscow, St. Petersburg, New York : Elima, Piter, 2006.

Globalistika: Entsiklopediya [Globalistics: Encyclopedic Dictionary] / ed. by I. I. Mazur, A. N. Chumakov. Moscow : Dialog, 2003.

Globalnye problemy sovremennosti [Global Problems of our Time] / ed. by N. N. Inozemtsev. Moscow : Mysl', 1981.

Gorbachev M. S. Perestrojka i novoe myshleniye [Restructuring and New Thinking]. Moscow : Politizdat, 1987.

Zagladin V. V., Frolov I. T. Globalnye problemy sovremennosti: nauchnye i sotsialnye aspekty [Global Problems of our Time: Scientific and Social Aspects]. Moscow : Mezhdunarodnyye otnosheniya, 1981.

Gelovani V. A. Problemy komp'yuternogo modelirovaniya [Problems of Computer Modeling]. Moscow : MNIIPU, 1978. 
Gerasimov I. P. Sovetskaya konstruktivnaya geografiya [Soviet Constructive Geography]. Moscow : Nauka, 1976.

Gvishiani D. M. Metodologicheskie problemy modelirovaniya globalnogo razvitiya [Methodological Problems of Global Development Modeling]. Moscow, 1977.

Maksimova M. M. Evropejskoe soobschestvo: regulirovanie integratsionnyh protsessov [European Community: Regulation of Integration Processes]. Moscow : Nauka, 1986.

Marx K., Engels F. Nemetskaya ideologiya [German Ideology] / K. Marx, F. Engels // Sochineniya [Compositions]: in 55 vols. $2^{\text {nd }}$ ed. Vol. 3. Moscow : Gos. izd-vo polit. lit-ry, 1955. Pp. 7-544.

Medouz D. Predely rosta [Growth Limits]. Moscow : MSU Press, 1991.

Moiseev N. N., Aleksandrov V. A., Tarko A. M. Chelovek i biosfera: Opyt sistemnogo analiza i eksperimenty s modelyami [Human and Biosphere: Experiences of Systems Analysis and Experiments with Models]. Moscow : Nauka. 1985.

Sotsializm i progress chelovechestva. Globalnye problemy tsivilizatsii [Socialism and Human Progress. Global Problems of Civilization]. Moscow : Politizdat, 1987.

Sotsializm i progress chelovechestva. Global'nyye problemy tsivilizatsii [Socialism and Human Progress. Global Problems of Civilization] / ed. by I. T. Frolov. Moscow : Politizdat, 1987. 